\title{
Erratum to: A disposable biosensor for the determination of alpha-amylase in human saliva
}

\author{
Mika Mahosenaho • Felice Caprio • Laura Micheli • \\ Adama M. Sesay • Giuseppe Palleschi • Vesa Virtanen
}

Published online: 19 February 2013

(C) Springer-Verlag Wien 2013

Erratum to: Microchim Acta (2010) 170:243-249

\section{DOI 10.1007/s00604-010-0360-y}

The original version of this paper, unfortunately, contained an error in Table 1. Most of the values given in the table are incorrect.

The correct Table 1 is presented below.

Table 1 Linear measurement ranges, detection limits and sensitivity for glucose, maltose and maltotriose activity in phosphate buffer using the same electrode $(n=6)$

\begin{tabular}{llll}
\hline & Glucose & Maltose & Maltotriose \\
\hline Range & $5-200 \mu \mathrm{M}$ & $1-100 \mathrm{mM}$ & $10-100 \mathrm{mM}$ \\
LOD & $5 \mu \mathrm{M}$ & $1 \mathrm{mM}$ & $20 \mathrm{mM}$ \\
Sensitivity & $30 \mathrm{~A} / \mathrm{Mcm}^{2}$ & $240 \mathrm{~mA} / \mathrm{Mcm}^{2}$ & $4 \mathrm{~mA} / \mathrm{Mcm}^{2}$ \\
\hline
\end{tabular}

The online version of the original article can be found at http://dx.doi.org/ 10.1007/s00604-010-0360-y.

M. Mahosenaho $\cdot$ A. M. Sesay $\cdot$ V. Virtanen

Laboratory of Biotechnology, Kajaani University consortium,

Oulu University, Salmelantie 43,

Sotkamo 88600, Finland

F. Caprio • L. Micheli $(\bowtie) \cdot$ G. Palleschi

Dipartimento di Scienze e Tecnologie Chimiche,

University of Rome "Tor Vergata", Via della Ricerca Scientifica,

00133 Rome, Italy

e-mail: micheli@uniroma2.it 